\title{
Markedly Improved Success Rate of Endoscopically Assisted Third Ventriculostomy Is Achieved by Routine Placement of External Lumbar Drain
}

\author{
Justen Watkins ${ }^{1} \quad$ Marc Cabanne $^{1} \quad$ Dan Miulli $^{1}$ \\ ${ }^{1}$ Department of Neurosurgery, Arrowhead Regional Medical Center, \\ Colton, California, United States \\ J Neurol Surg Rep 2017;78:e71-e76.

\begin{abstract}
Address for correspondence Justen Watkins, DO, Department of Neurosurgery, Riverside University Health System Medical Center, 26250 Cactus Avenue, Suite A2006, Moreno Valley, CA 92555, United States (e-mail: justen.watkins@icloud.com).
\end{abstract}

\begin{abstract}
Hydrocephalus is a major cause of patient decreased quality of life and high health care financial burden in the United States and throughout the world. The placement of ventricular shunts (ventriculoperitoneal shunt) has proven to be a safe treatment for hydrocephalus, but it is associated with a high complication rate leading to a lower quality of life and continued financial burden for patients, their families, and society as a whole. The endoscopically assisted third ventriculostomy (ETV) has been practiced as an alternative to ventricular shunting since the 1990s. Success rates vary widely and there are many factors which contribute to the varying success rates. The ETV procedure has the potential to alleviate much of the overall quality of life issues and some of the financial burdens associated with hydrocephalus provided success rates

\section{Keywords}

- endoscopically assisted third ventriculostomy

- lumbar drain

- hydrocephalus

- ventriculoperitoneal shunt

- ventricular shunt

- ventricle

- cerebrospinal fluid

- brain tumor

- hemorrhagic stroke

- cerebral hemorrhage

- neurocysticercosis can be increased and the procedure and management techniques are adopted more widely. Common techniques have been published in the past which report associated improvements in success rates amongst individual surgeons. Here, we report a novel perioperative technique and management strategy that displays a higher than reported success rate. Our methods and results show potential to significantly improve overall ETV success rates if reproduced and subsequently adopted widely. We retrospectively studied records of 24 adult patients with hydrocephalus who were treated with an ETV procedure. Routinely, we placed an external lumbar drain postoperatively which was continued for a minimum of 2 days. There was a $95.8 \%$ success rate at 30 days. The overall success rate was $83.3 \%$. This is significantly higher than the average of the predicted success scores calculated by the ETV success scoring system (71.8\%). It is also significantly higher than previous studies' reported ETV success rates in adults. We propose additional similar studies to be performed to test the reproducibility of increased success rates using our technique, ideally through a prospective, randomized, multicenter trial.
\end{abstract}

\section{Background}

Hydrocephalus is a well-described condition without medical treatment. ${ }^{1-4}$ Debilitating and life-threatening in its effects, this disease has been historically formidable for physicians to treat. ${ }^{3,5-8}$ As modern neurosurgery has matured over the last century many options for treatment have blossomed and thus millions of patients have benefited. As surgical procedures and implantation of permanent devices such as ventricular shunts have become mainstream received

September 7, 2016 accepted after revision February 10, 2017
DOI http://dx.doi.org/ 10.1055/s-0037-1600915. ISSN 2193-6358.
๑) 2017 Georg Thieme Verlag KG
Stuttgart · New York

License terms

(요 (1) $\Theta \circledast$ 
treatment modalities since the mid-20th century, ${ }^{9}$ the overall monetary cost of this disease on societies has consequently increased. ${ }^{10}$ Ventricular shunting operations and revisions account for over a billion U.S. dollars per year of medical expenditure in the United States alone. ${ }^{11}$ Furthermore, patients living with hydrocephalus, and their families, continue to suffer decreased quality of life and financial burdens resulting from the frequent complications attributable to the inherent difficulties associated with this disease and the contemporary treatments. ${ }^{8,12-14}$

Successful treatment of hydrocephalus by third ventriculostomy was first described in the 1920 s. ${ }^{15}$ Endoscopically assisted third ventriculostomy (ETV), developed in the 1990s utilizing modern technology to more safely perform the original technique, has become a commonly used treatment for many forms of hydrocephalus either as a primary treatment and alternative to ventricular shunting or as a secondary treatment following shunt failure. ${ }^{2,16-18}$

The achievement of increased ETV success rates has the potential to drastically improve patients' quality of life and reduce individual, familial, and societal financial burdens. ${ }^{10,11,13}$ ETV failure has been described as the persistence or recurrence of clinical hydrocephalus which requires surgical treatment following an ETV procedure on a patient. $^{5,19}$ ETV success and failure has been extensively reported and ETV failure predictive factors with an ETV success scoring system (ETVSS) for childhood hydrocephalus have been proposed, reproduced, and widely adopted. ${ }^{16,19-23}$ Differences in success rates varying across the age spectrum have been identified. ${ }^{24,25}$ Case series along with associated success rates of ETVs are frequently published, and the rates vary widely (from 60.9 to $78.3 \%$ in our literature review). ${ }^{20-22,25-30}$

As reported recently by Ozisik et al, ETV success rates can be improved by augmentation of caudal cerebrospinal spinal fluid (CSF) flow through continuous lumbar drainage (CLD) facilitated with the placement of an external lumbar drain (ELD). ${ }^{31}$ The rationale behind this practice is based on two hypotheses. First, continuous caudal CSF flow naturally promotes patency of the stoma created by an ETV through an inhibiting effect on regrowth of Liliequist membrane. Second, in cases where increased protein in the CSF is a contributing factor to decreased absorption at the cortical subarachnoid space, drainage, and removal of CSF would theoretically aid in clearance of and a decrease in CSF protein, therefore increasing the likelihood of ETV success.

\section{Objective}

We analyzed the practice of routinely placing an ELD in conjunction with ETV, which is in contrast to previously published practices which only selectively place an ELD when ETV is performed or after sign of failure. ${ }^{31,32}$ Noting that ETV success rates have shown improvement with occasional, selective use of ELD, we hypothesized that routine ELD placement and CLD on all patients undergoing ETV would demonstrate even higher success rates in a significantly measurable way. The increased success rates would be in comparison to average predicted ETVSS and reported success rates of previously published standard ETV case series.

\section{Methods}

\section{Prereview}

This was a retrospective, multisurgeon, single-institution study to evaluate the effectiveness of routine ELD placement and CLD following ETV procedure on patients with hydrocephalus. Our primary hypothesis was that routine ELD placement on patients undergoing ETV procedure would lead to an increased ETV success rate. The study was approved by the institution's Internal Review Board. All applicable laws (HIPAA and state and local laws) and regulations were strictly observed during the study. It was performed with volunteer efforts alone; no financial or tangible material compensation was involved.

\section{Inclusion Criteria}

The inclusion criterion was any patient with hydrocephalus who underwent an ETV procedure with routine ELD over the previous 6 years (2009-2015). All patients received an ELD in conjunction with the performance of the ETV, and the ELD was placed in the operating room immediately following the ETV procedure. There were no prescreening or selection criteria for placement of the drain.

\section{Endoscopically Assisted Third Ventriculostomy}

All patients were treated and managed at the sponsoring institution. An informed consent was obtained from each patient and next-of-kin before every procedure. The ETV procedures were performed under similar conditions, that is, inpatient scheduled surgery performed in the operating theater, under general anesthesia, with sterile procedures and equipment. In all cases, a right-sided approach was used and a small burr hole was made with a port placed through the meninges and brain parenchyma to access the ventricular space. Then a videoscope was inserted and manipulated by the surgeon. The third ventricle was identified, entered, and a stoma was created on the floor of the third ventricle anterior to the maxillary bodies.

\section{Lumbar Drain}

All patients received an ELD as a routine placement immediately following ETV procedure and before exiting the operating room. The ELD's were kept in place for a minimum of 48 hours post-ETV and were discontinued solely at the discretion of the surgeon. The basis for discontinuation was a combination of indicators including the patient's neurological examination, CSF protein levels, and head computer tomography imaging studies. Neither laboratory nor imaging studies were routinely obtained for determination of discontinuation of ELD.

The lumbar drain was uniformly managed on all patients immediately following placement. All patients were admitted to intensive care units following surgery. The ELD was kept open and the level was titrated to achieve a drainage 
goal of 10 to $15 \mathrm{~mL} / \mathrm{h}$ in a continuous fashion (i.e., not an intermittent, hourly drainage). After 48 hours, the ELD could be discontinued if the patient was neurologically stable. In most cases, the ELD was removed after the 48 hour period. A minority of patients received continued drainage for an extended period due to persistence or development of new neurological symptoms. In all cases, the ELD was successfully weaned over several days.

\section{Endoscopically Assisted Third Ventriculostomy Failure}

ETV failure for this study was defined as persistence or return of hydrocephalus which required intervention with a repeat ETV or placement of a permanent ventricular shunt. In addition, we analyzed ETV failure on a stratified basis. ETV failure was identified as either EARLY ( $<30$ days) or LATE ( $<30$ days) failures. We measured the days to ETV failure as being days after initial ETV when a repeated intervention was performed (EVD, repeat ETV, or VPS).

\section{Data Collection and Analysis}

A database search was conducted using the neurosurgery census from January 2009 to December 2015. All medical records from patients during that time period who underwent an ETV were reviewed. Reviews focused on each patient's history of present illness, diagnostic information, and assessments, treatments rendered, and response to treatments, including failures and need for retreatment. All patients meeting inclusion criteria were included in the study. The data which were collected included age, sex, diagnosis, and etiology (including pathology, cytology, microbiology, and laboratory studies), ETVSS, verification of performance of ETV and ELD, time of ELD drainage postoperative, final CSF protein level taken just before removal of the drain, and any invasive procedure(s) performed to treat hydrocephalus following ETV (excluding initial ELD).

Characteristics of patients in the failure group were analyzed included etiology. The ETVSS for the failure group and the success group was analyzed and the respective median value for each was reported, along with the overall mean ETVSS for all patients.

The time to ETV failure was calculated and recorded for each ETV failure patient. The final protein levels were analyzed for the failure group and reported as a mean value. The EARLY and LATE failure rates were analyzed separately and overall failure rate was calculated as a percentage. The overall failure rate was compared with previously reported failure rates.

\section{Results}

A total of 27 adult patients underwent ETVs during the time period reviewed. Age range includes 18 to 66 years. There were a total of 7 females (32\%) and 15 males (68\%). Three patients (aged 18, 38, and 60 years) were excluded from the study due to ELD not being placed immediately postoperatively. The study included a total of 24 patients ( $n=24$ ) with ages ranging from 23 to 66 years. The mean age was 46.5 years. Etiologies of hydrocephalus (see - Fig. 1) requiring ETV were varied and

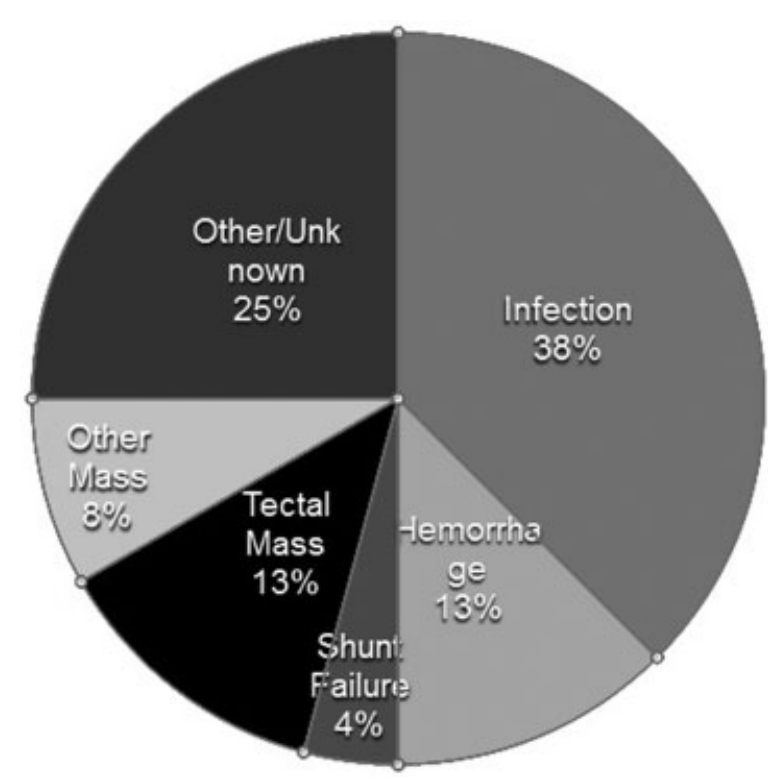

Fig. 1 Etiology of hydrocephalus.

ncluded postinfectious ( $9=37.5 \%)$, Intracerebral hemorrhage $(\mathrm{ICH}) /$ intraventricular hemorrhage $(\mathrm{IVH})(3=12.5 \%)$, ventricular shunt failure $(1=4.2 \%)$, nontectal mass $(3=12.5 \%)$, tectal mass $(2=8.3 \%)$, other/unknown cause $(6=25 \%)$. The calculated ETVSS for all patients in the study ranged from 60 to $80 \%$, with a mean of $72.5 \%$. The failure group's median ETVSS was $60 \%$. The success group's median ETVSS was $80 \%$. The number of ELD days was also recorded and ranged from 2 to 28 days, with a median ELD days of 2.5.

Amongst the 24 patients in our study group, there were a total of 20 successes which did not need subsequent surgical treatment for hydrocephalus. In addition, there were a total of four ETV failures (see - Table 1). The most common etiology of hydrocephalus corresponding to a failed ETV was an infection, specifically, neurocysticercosis (responsible for three failures). There was one lone failure with a separate etiology of IVH. Amongst the failures group, the final CSF protein levels taken just before the failure ranged from 33 to $293 \mathrm{~g} / \mathrm{dL}$. The mean final CSF protein level amongst the failure group was $63 \mathrm{~g} / \mathrm{dL}$. The days to failure were recorded as ranging from 28 to 94 days following ETV. The median days to ETV failure was 35.5 days. Only one patient had an EARLY failure (within 30 days). This corresponds with a $95.8 \%$ success rate at 30 days. The days to failure were 28 for the single case of EARLY failure. In addition, there were a total of three LATE failures (after 30 days), with the days to failure amongst the LATE failures ranging from 32 to 94 days. The total ETV failures compared with overall ETV cases corresponds to an overall ETV success rate of 83.3\% (20 of 24).

\section{Discussion}

Previously reported adult and children patients primary ETV case series' success rates $20,24,26-29,33$ vary from 60.9 to $78.3 \%$ 
Table 1 Series of adult patients who received ETVs with routine ELD placement and results

\begin{tabular}{|c|c|c|c|c|c|c|c|c|}
\hline Patient & Age (y) & Sex & $\begin{array}{l}\text { ELD } \\
\text { placed } \\
\text { in OR }\end{array}$ & $\begin{array}{l}\text { ETV fail- } \\
\text { ure }\end{array}$ & $\begin{array}{l}\text { Days } \\
\text { until } \\
\text { failure }\end{array}$ & $\begin{array}{l}\text { Days of } \\
\text { ELD }\end{array}$ & Cause of HCP & $\begin{array}{l}\text { Final CSF } \\
\text { protein }\end{array}$ \\
\hline 1 & 25 & $\mathrm{M}$ & $Y$ & $\mathrm{~N}$ & & 2 & $\begin{array}{l}\text { Cerebral } \\
\text { coccidioidomycosis }\end{array}$ & 293 \\
\hline 2 & 66 & $\mathrm{~F}$ & $\mathrm{Y}$ & $\mathrm{N}$ & & 14 & $\mathrm{ICH}$ no IVH & 63 \\
\hline 3 & 61 & $\mathrm{~F}$ & $Y$ & $Y$ & 32 & 6 & IVH & Unknown \\
\hline 4 & 36 & $M$ & $\bar{Y}$ & $\mathrm{~N}$ & & 28 & Cysticercosis & 101 \\
\hline 5 & 54 & $\mathrm{~F}$ & $\mathrm{Y}$ & $\mathrm{N}$ & & 4 & Cysticercosis & Unknown \\
\hline 6 & 37 & M & $Y$ & $\mathrm{~N}$ & & 2 & Unknown & Unknown \\
\hline 7 & 43 & $\mathrm{~F}$ & $Y$ & $\mathrm{~N}$ & & 3 & Cysticercosis & Unknown \\
\hline 8 & 30 & $M$ & $Y$ & $\mathrm{~N}$ & & 2 & Unknown & 41 \\
\hline 9 & 46 & $\mathrm{M}$ & $\mathrm{Y}$ & $\mathrm{N}$ & & 2 & Unknown & 37 \\
\hline 10 & 29 & M & $\mathrm{Y}$ & $\mathrm{Y}$ & 39 & 2 & Cysticercosis & 51 \\
\hline 11 & 23 & $\mathrm{~F}$ & $Y$ & $\mathrm{~N}$ & & 2 & Unknown & 109 \\
\hline 12 & 59 & $\mathrm{~F}$ & $Y$ & $\mathrm{~N}$ & & 2 & Aneurysmal SAH & 50 \\
\hline 13 & 56 & $\mathrm{M}$ & $Y$ & $Y$ & 94 & 4 & Cysticercosis & 104 \\
\hline 14 & 66 & $\mathrm{~F}$ & $\mathrm{Y}$ & $\mathrm{N}$ & & 2 & Unknown & 211 \\
\hline 15 & 35 & $\mathrm{M}$ & $Y$ & $Y$ & 28 & 2 & Cysticercosis & 33 \\
\hline 16 & 60 & $\mathrm{M}$ & $Y$ & $\mathrm{~N}$ & & 4 & Metastatic melanoma & 128 \\
\hline 17 & 55 & $\mathrm{M}$ & $Y$ & $\mathrm{~N}$ & & 2 & Neurosyphilis & 128 \\
\hline 18 & 55 & M & $\mathrm{Y}$ & $\mathrm{N}$ & & 4 & Unruptured AVM & 128 \\
\hline 19 & 52 & $\mathrm{M}$ & $Y$ & $\mathrm{~N}$ & & 3 & Benign tectal mass & $<4$ \\
\hline 20 & 24 & $\mathrm{M}$ & $Y$ & $\mathrm{~N}$ & & 5 & VPS failure & 98 \\
\hline 21 & 53 & $\mathrm{M}$ & $\mathrm{Y}$ & $\mathrm{N}$ & & 2 & Metastatic melanoma & Unknown \\
\hline 22 & 46 & M & Y & N & & 3 & $\begin{array}{l}\text { Cryptococcal } \\
\text { meningitis }\end{array}$ & 187 \\
\hline 23 & 58 & M & $\mathrm{Y}$ & $\mathrm{N}$ & & 17 & Pineocytoma & 89 \\
\hline 24 & 48 & $\mathrm{M}$ & $\mathrm{Y}$ & $\mathrm{N}$ & & 3 & Colloid cyst & 217 \\
\hline
\end{tabular}

Abbreviations: AVM, arteriovenous malformation; CSF, cerebrospinal fluid; ELD, external lumbar drain; ETV, endoscopically assisted third ventriculostomy; F, female; HCP, hydrocephalus; ICH, intracerebral hemorrhage; IVH, intraventricular hemorrhage; M, male; n, no; OR, operating room; SAH, subarachnoid hemorrhage; VPS, ventriculoperitoneal shunt; y, yes.

(see - Fig. 2). The mean reported success rate from these papers is $72 \%$. The most commonly reported finding in multiple studies is that ETVs performed for tumors and anatomical obstructive hydrocephalus correlate with higher success rates than when performed for hemorrhages and infections. ${ }^{28,33}$ Our study reports a series with 12 of $24(50 \%)$ of the cases being caused by either infection or hemorrhage (see - Fig. 1). Taking into account the etiology, following the standard ETV technique, the success rate from our study population would likely be substantially smaller than was observed with the ELD drainage.

The method of routine ELD placement with CLD following ETV described in this article is unique, as none of the previously published articles reporting ETV case series described similar methods. Only one article by Ozisik et al, ${ }^{31}$ studied the selective use of ELD's following ETV in 22 all pediatric patients, and some of the ELD's were placed at varying times postoperatively. Their article did report an overall decrease in ETV failure through the select use of ELD. Interestingly, their overall ETV success rate was very similar to ours ( 81.8 vs. $83.3 \%$ ). They offer a hypothesis for the increased success rate, mentioning the possibility of "recovering absorption capacity following ETV." They concluded that ELD should be considered before considering ETV as a failure.

Further comparison of results between these two studies yielded additional information. They reported that their results indicated a majority of failures occur within 30 days postoperatively (EARLY failures). In an analysis of the failure group in our study, the majority of failures (75\%) occurred LATE (after 30 days). While not immediately provable, this would suggest that our methods have the effect of markedly reducing EARLY failures (EARLY success rate of 95.8\%). 


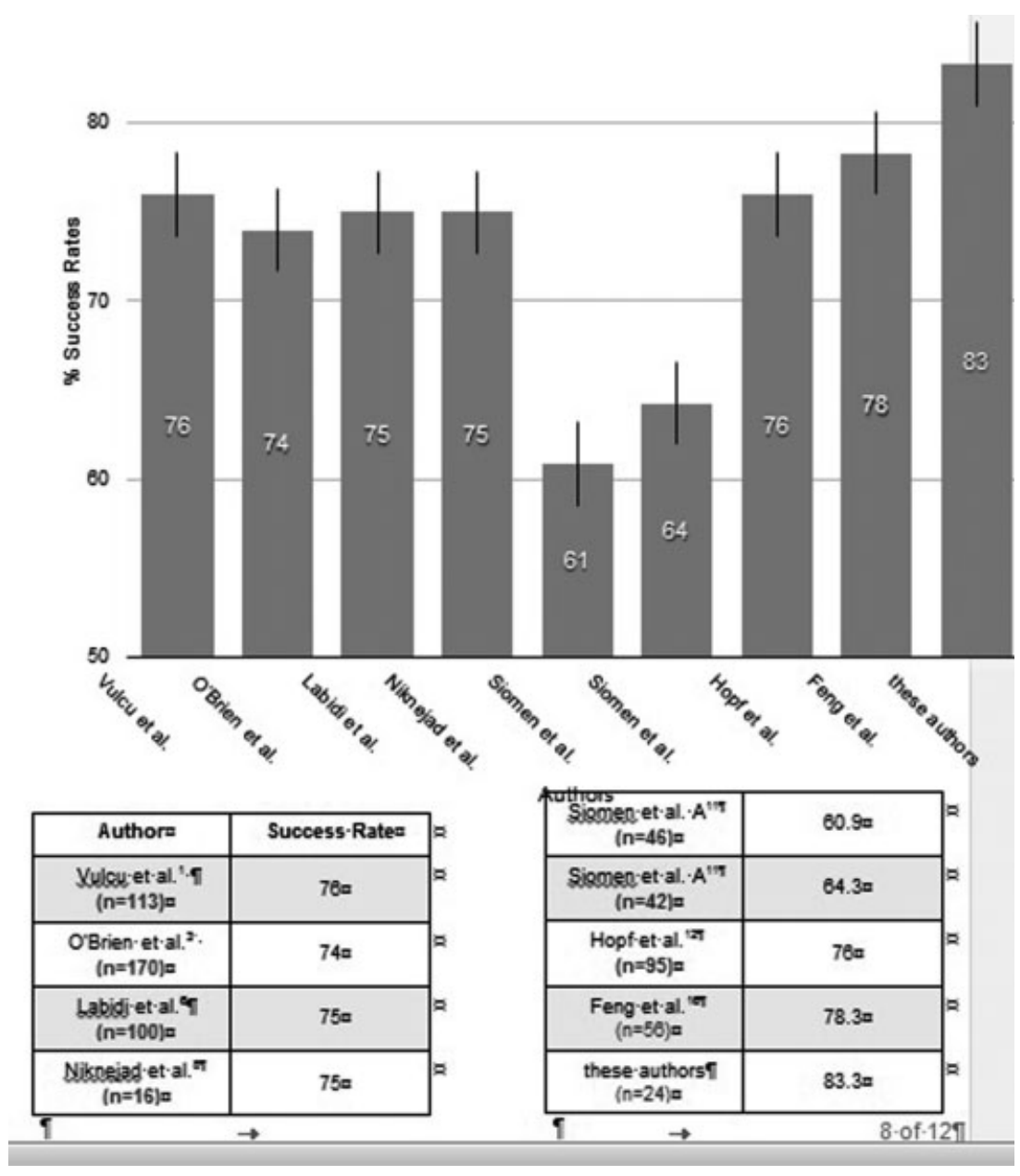

Fig. 2 Comparison of overall ETV success rates between published case series of adult patients. ETV, endoscopically assisted third ventriculostomy.

\section{Limitations}

This study has several limitations. First, it is a retrospective review. A future study would ideally be performed in a prospective manner. In addition, as all of the patients received a routine ELD postoperatively, there was no internal control group and the study was not randomized. Subsequent studies would be benefited by providing randomization to serve as a control mechanism. Another limitation identified was that although there were multiple primary surgeons performing the operations and overseeing the ELD management, the records that were reviewed were from a single institution. An improvement for this limitation would include a multicenter analysis. Further limitations include relatively small study size, unrecorded variations in decision criteria for discontinuing the ELD, disproportionately lower number of females, and the absence of pediatric patients included in the study.

\section{Conclusions}

Avoidance of ventricular shunt placement in patients with hydrocephalus by successful treatment via less burdensome and less costly means would likely lead to improved quality of life and decreased financial burden on patients, their families as well as society. Innovations in ETV techniques and perioperative management strategies that increase success rates have the potential to drastically improve these measures.

Here, we have described a technique and perioperative management strategy that is shown to significantly increase the success rate of ETV procedures on patients. We propose that additional studies be performed following this protocol and reporting of the results. A prospective, randomized, multicenter trial could feasibly be conducted. Ultimately, if the results are reproduced with significant numbers, wider adoption of this technique could potentially translate into a substantial improvement of patient, familial, and societal burdens.

\section{References}

1 Rekate HL, Nadkarni TD, Wallace D. The importance of the cortical subarachnoid space in understanding hydrocephalus. J Neurosurg Pediatr 2008;2(01):1-11

2 Vogel TW, Bahuleyan B, Robinson S, Cohen AR. The role of endoscopic third ventriculostomy in the treatment of hydrocephalus. J Neurosurg Pediatr 2013;12(01):54-61 
3 Rahme R, Bojanowski MW. Internal hydrocephalus, external hydrocephalus, and the syndrome of intracerebral cerebrospinal fluid entrapment: a challenge to current theories on the pathophysiology of communicating hydrocephalus. Med Hypotheses 2010;74(01):95-98

4 Dandy WE, Blackfan KD. An experimental and clinical study of internal hydrocephalus. JAMA 1913;61(25):2216-2217. doi: 10.1001/jama.1913.04350260014006

5 Fabiano AJ, Doyle K, Grand W. Delayed stoma failure in adult communicating hydrocephalus after initial successful treatment by endoscopic third ventriculostomy: case report. Neurosurgery 2010;66(06):E1210-E1211, discussion E1211

6 Bouras T, Sgouros S. Complications of endoscopic third ventriculostomy. World Neurosurg 2013;79(2, Suppl):22.e9-22.e12

7 Cinalli G, Spennato P, Ruggiero C, et al. Intracranial pressure monitoring and lumbar puncture after endoscopic third ventriculostomy in children. Neurosurgery 2006;58(01):126-136, discussion 126-136

8 Korinek AM, Fulla-Oller L, Boch AL, Golmard JL, Hadiji B, Puybasset L. Morbidity of ventricular cerebrospinal fluid shunt surgery in adults: an 8-year study. Neurosurgery 2011;68(04):985-994, discussion 994-995

9 Nulsen FE, Spitz EB. Treatment of hydrocephalus by direct shunt from ventricle to jugular vain. Surg Forum 1951;•*0:399-403

10 Garton HJLMD, Kestle JR, Cochrane DD, Steinbok P. A cost-effectiveness analysis of endoscopic third ventriculostomy. Neurosurgery 2002;51(01):69-77, discussion 77-78

11 Patwardhan RVMD, Nanda A. Implanted ventricular shunts in the United States: the billion-dollar-a-year cost of hydrocephalus treatment. Neurosurgery 2005;56(01):139-144, discussion 144-145

12 Xu R, McCrea HJ, Hoffman CE, Souweidane MM, Greenfield JP. The Impact of Endoscopic Third Ventriculostomy on Shunt Revision Rate: A 14-Year Experience at a Single Institution. World Neurosurg 2015;84(03):677-680.e1

13 Shannon CN, Simon TD, Reed GT, et al. The economic impact of ventriculoperitoneal shunt failure. J Neurosurg Pediatr 2011; 8(06):593-599

14 Kulkarni AV, Shams I. Quality of life in children with hydrocephalus: results from the Hospital for Sick Children, Toronto. J Neurosurg 2007;107(5, Suppl):358-364

15 Mixter WJ. Ventriculoscopy and puncture of the floor of the third ventricle. Boston Med Surg J 1923;188:277-278. doi: 10.1056/ NEJM192303011880909

16 Jenkinson MD, Hayhurst C, Al-Jumaily M, Kandasamy J, Clark S, Mallucci CL. The role of endoscopic third ventriculostomy in adult patients with hydrocephalus. J Neurosurg 2009;110(05): 861-866

17 Kulkarni AV, Drake JM, Mallucci CL, Sgouros S, Roth J, Constantini S; Canadian Pediatric Neurosurgery Study Group. Endoscopic third ventriculostomy in the treatment of childhood hydrocephalus. J Pediatr 2009;155(02):254-9.e1

18 Melikian A, Korshunov A. Endoscopic third ventriculostomy in patients with malfunctioning CSF-shunt. World Neurosurg 2010; 74(4-5):532-537
19 García LG, López BR, Botella GI, et al. Endoscopic Third Ventriculostomy Success Score (ETVSS) predicting success in a series of 50 pediatric patients. Are the outcomes of our patients predictable? Childs Nerv Syst 2012;28(08):1157-1162

20 Labidi M, Lavoie P, Lapointe G, et al. Predicting success of endoscopic third ventriculostomy: validation of the ETV Success Score in a mixed population of adult and pediatric patients. J Neurosurg 2015;123(06):1447-1455

21 Brockmeyer D, Abtin K, Carey L, Walker ML. Endoscopic third ventriculostomy: an outcome analysis. Pediatr Neurosurg 1998; 28(05):236-240

22 Di Rocco C, Frassanito P, Massimi L, Tamburrini G. Prediction of outcome of endoscopic third ventriculostomy. World Neurosurg 2013;80(05):509-511

23 Kulkarni AV, Drake JM, Kestle JRW, Mallucci CL, Sgouros S, Constantini S; Canadian Pediatric Neurosurgery Study Group. Predicting who will benefit from endoscopic third ventriculostomy compared with shunt insertion in childhood hydrocephalus using the ETV Success Score. J Neurosurg Pediatr 2010;6(04): 310-315

24 Niknejad HR, Depreitere B, De Vleeschouwer S, Van Calenbergh F, van Loon J. Results of endoscopic third ventriculostomy in elderly patients $\geq 65$ years of age. Clin Neurol Neurosurg 2015;130:48-54

25 Beems T, Grotenhuis JA. Is the success rate of endoscopic third ventriculostomy age-dependent? An analysis of the results of endoscopic third ventriculostomy in young children. Childs Nerv Syst 2002;18(11):605-608

26 Vulcu S, Eickele L, Cinalli G, Wagner W, Oertel J. Long-term results of endoscopic third ventriculostomy: an outcome analysis. J Neurosurg 2015;123(06):1456-1462

27 O'Brien DF, Javadpour M, Collins DR, Spennato P, Mallucci CL. Endoscopic third ventriculostomy: an outcome analysis of primary cases and procedures performed after ventriculoperitoneal shunt malfunction. J Neurosurg 2005;103(5, Suppl):393-400

28 Hopf NJ, Grunert P, Fries G, Resch KD, Perneczky A. Endoscopic third ventriculostomy: outcome analysis of 100 consecutive procedures. Neurosurgery 1999;44(04):795-804, discussion 804-806

29 Feng H, Huang G, Liao X, et al. Endoscopic third ventriculostomy in the management of obstructive hydrocephalus: an outcome analysis. J Neurosurg 2004;100(04):626-633

30 Appelgren T, Zetterstrand S, Elfversson J, Nilsson D. Long-term outcome after treatment of hydrocephalus in children. Pediatr Neurosurg 2010;46(03):221-226

31 Ozisik P, Roth J, Beni-Adani L, Constantini S. Continuous spinal drain following endoscopic third ventriculostomy: a proposal to change the definition of failure. Childs Nerv Syst 2011;27(11): 1973-1978

32 Chowdhry SA, Cohen AR. Intraventricular neuroendoscopy: complication avoidance and management. World Neurosurg 2013;79 (2, Suppl):15.e1-15.e10

33 Siomin V, Cinalli G, Grotenhuis A, et al. Endoscopic third ventriculostomy in patients with cerebrospinal fluid infection and/or hemorrhage. J Neurosurg 2002;97(03):519-524 